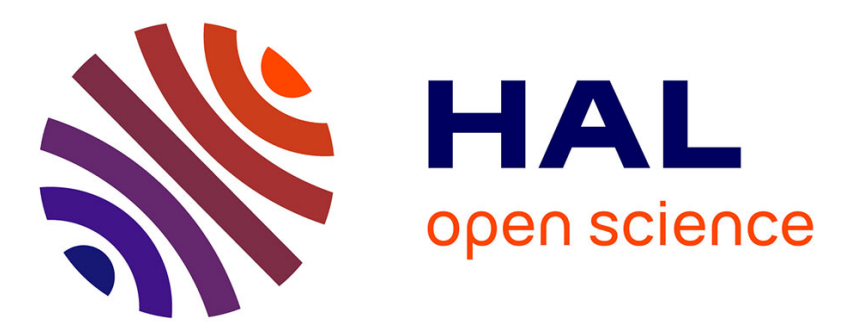

\title{
Predictors of problem drinking in adolescence and young adulthood
}

Evelien A. P. Poelen, Rutger C. M. E. Engels, Ron H. J. Scholte, Dorret I.

Boomsma, Gonneke Willemsen

\section{- To cite this version:}

Evelien A. P. Poelen, Rutger C. M. E. Engels, Ron H. J. Scholte, Dorret I. Boomsma, Gonneke Willemsen. Predictors of problem drinking in adolescence and young adulthood. European Child and Adolescent Psychiatry, 2009, 18 (6), pp.345-352. 10.1007/s00787-009-0736-x . hal-00478095

\section{HAL Id: hal-00478095 https://hal.science/hal-00478095}

Submitted on 30 Apr 2010

HAL is a multi-disciplinary open access archive for the deposit and dissemination of scientific research documents, whether they are published or not. The documents may come from teaching and research institutions in France or abroad, or from public or private research centers.
L'archive ouverte pluridisciplinaire HAL, est destinée au dépôt et à la diffusion de documents scientifiques de niveau recherche, publiés ou non, émanant des établissements d'enseignement et de recherche français ou étrangers, des laboratoires publics ou privés. 
Evelien A.P. Poelen

Rutger C.M.E. Engels

Ron H.J. Scholte

Dorret I. Boomsma

Gonneke Willemsen

Received: 14 February 2008

Accepted: 14 October 2008

Published online: 5 February 2009

E.A.P. Poelen $(\varangle) \cdot$ R.C.M.E. Engels

R.H.J. Scholte

Behavioural Science Institute

Radboud University Nijmegen

P. O. Box 9104

6500 HE Nijmegen, The Netherlands

Tel.: +31-24/361-5767

Fax: +31-24/361-2776

E-Mail: e.poelen@pwo.ru.nl

D.I. Boomsma · G. Willemsen

Biological Psychology

VU University Amsterdam

Van der Boechorststraat 1

1081 BT Amsterdam, The Netherlands

\section{Predictors of problem drinking in adolescence and young adulthood}

A longitudinal twin-family study
Abstract We examined drinking behavior of parents, siblings, and friends of twins as predictors of adolescent and young adult problem drinking over a period of 2 and a period of 7 years. Data of 12 to 30 -year-old twins and their family members from the Netherlands Twin Register were analyzed. Problem drinking in twins was assessed in 1995 and 2000 and was defined based on the CAGE and amount of drinking. Data on alcohol use of parents, siblings and friends were collected in 1993. Multinomial logistic regression analyses were used to examine the short-term (1993-1995; $n=2,994)$ and the long-term longitudinal predictors (1993-2000; $n=1,796)$ of problem drinking. Age, sex and own alcohol use in 1993 explained $25 \%$ of the variance in adolescent and young adult problem drinking. Moreover, adolescents and young adults with fathers who drank frequently and with a large numbers of drinking friends, were at the highest risk for problem drinking 2 years later. Over a period of 7 years the number of drinking friends was no longer a risk factor, but few times a week or daily alcohol use of fathers remained a risk factor for later problem drinking. Drinking behavior of mother and siblings did not substantially predict problem drinking. Sex and age did not moderate these effects.

Key words problem drinking adolescents - young adults family - friends - longitudinal

\section{Introduction}

Recent figures on alcohol use in the Dutch population of 12 years and older show that $20 \%$ of the males and $5 \%$ of the females drink heavily, which is defined as drinking at least six drinks at one or more days a week [21]. The prevalence is particularly high among young people in the age of $18-24$ with $39 \%$ of the males and $9 \%$ of the females being heavy drinkers. Problem drinking refers to individuals who drink above a certain threshold and as a consequence experience problems related to their alcohol consumption.
Prevalence rates of problem drinking peak at the same age as prevalence rates of heavy drinking; while the average among 16 to 70 -year olds is $17 \%$ for males and $4 \%$ for females [33], during late adolescence and young adulthood (16-24 year of age), $34 \%$ of the males and $9 \%$ of the females are identified as a problem drinker. Heavy alcohol use and problem drinking in young people is associated with short-term consequences such as alcohol related violence, drunk driving, injuries, risky sexual behavior and school problems $[14,17,36]$, and is predictive of problematic alcohol use in adulthood $[19,22]$. These negative consequences call for extensive study of the predictors 
of adolescent and young adult heavy drinking and problem drinking. Research on young people's drinking generally focuses on more normative drinking patterns. It has provided evidence for the predictive value of drinking of family members and friends for adolescent and young adult alcohol use [2, 26, 27, 39]. However, only few studies examined the etiology of heavy drinking $[13,27,35]$ and even less have focused on factors related to problem drinking in young people. The aim of this study is, therefore, to examine the role of the immediate social environment including parents, siblings and friends, on adolescent and young adult problem drinking.

Prior research on the effects of parental alcohol use on young people's drinking showed contradictory findings. Whereas some studies reported parental drinking to be related to problem drinking among adolescents [10], others found no significant associations [23]. One limitation of these studies was that they did not examine the effects of maternal and paternal alcohol use separately, but combined mothers' and fathers' drinking into one overall measure of parental alcohol use. This overall measure might not capture the entire impact of parental drinking given that drinking of fathers and mothers may have a unique influence on their offspring's problem drinking. Those few studies that studied these differential influences again reported mixed findings. Walden et al. [35] reported that both fathers' and mothers' drinking was related to adolescent heavy drinking, as did McGue et al. [20] who further showed this result to be stronger for biological than adoptive parents. In contrast, Reifman et al. [27] reported that only mother's drinking was related to heavy drinking among adolescents, while another study suggested that neither paternal nor maternal alcohol use was related to adolescent problem drinking [37].

Siblings and peers may also contribute to adolescent heavy drinking and problem drinking. Regarding the role of sibling drinking on problem drinking, only a small number of studies exist. Using data of adoptive siblings, McGue et al. [20] indicated that sibling's drinking is substantially related to adolescent alcohol misuse. In contrast, Windle [37] did not find a longitudinal relation between sibling's frequency of drinking and adolescent problem drinking.

Friends' drinking is seen as a robust predictor of young people's alcohol use in general $[1,2,7,12,24$, $32,38]$. In line with these studies longitudinal research on adolescent heavy alcohol use $[13,15,23,27$, $31]$ and problem drinking $[10,37]$ also found support for the importance of drinking of friends.

Thus, previous studies point to the relevance of family members' and friends' drinking in predicting adolescent and young adult problem drinking. Results of previous studies are mixed, possibly due to varying sample sizes, different statistical methods, sets of variables used, or confounders. With regard to the relative importance, Windle [37] reported that if parental, siblings', and friends' alcohol use were considered simultaneously in one longitudinal model, the effects of parental alcohol use were weakest. Other longitudinal studies simultaneously examining the roles of parents and friends (but not of siblings) found stronger effects for friends, with only significant effects of mother's drinking [27] or no significant effects of parents' drinking [23]. Ellickson et al. [10] showed that friends' drinking but not parents' drinking was significantly associated with problem drinking over a period of 2 years. However, over a period of 5 years, parental drinking was significantly associated with problem drinking, but friends' drinking was not anymore.

In sum, existing studies suggest that parents', siblings' and friends' drinking may be important in adolescent and young adult problem drinking, although results are somewhat mixed. However, the impact of parents, siblings and friends has seldom been examined simultaneously in a long-term longitudinal study. In the current study we examined to what extent drinking of parents, siblings, and friends was related to adolescent and young adult problem drinking over a period of 2 and 7 years. We further explored whether these associations were moderated by sex and age.

\section{Methods}

\section{Procedure and participants}

Data reported in this study are part of a longitudinal survey study of the Netherlands Twin Register. Data collection was started in 1991 and 1993 by recruiting adolescent twins aged 13-22 years and their families. Their addresses were obtained from city councils in the Netherlands. In later years, additional volunteer twin families also participated. Since 1991 adolescent twins and their families received surveys about health, lifestyle and personality approximately every 2 years. Twins were asked to participate every 2 years (1991, 1993, 1995, 1997, 2000, 2002 and 2004), parents in 1991, 1993, 1995, 2002 and 2004, and siblings from 1995 onwards. Some individuals participated only once, others participated several times. The majority (about $60 \%$ ) of the twins participated more than once. Moreover, previous examination of information of participants of the Netherlands Twin Register show that dropouts were not likely to cause bias, as there are few significant differences in the health and lifestyle measures (e.g., drinking and smoking) between 
dropouts and participating families [34]. Information about sample and data collection is described in more detail in Boomsma et al. $[5,6]$.

In the present study we used data from the 1993, 1995 , and 2000 surveys. At baseline the mean age was 17.8 years (SD 3.1) with an age range from 12 to 25 . Participants were grouped into three age groups. The youngest group consisted of 12 to 15-year olds and included all adolescents that were under the legal age to buy and drink alcohol. The second group contained middle and late adolescents aged 16-20. This age period is the period in which the adolescents are allowed to buy alcoholic beverages, and it is also the period during which Dutch adolescents start drinking regularly. The oldest age group consisted of 21 to 25 -year-old young adults and reflected the period in which individuals become more autonomous young adults who often leave home and are less guided by parental supervision and monitoring. The sample for the short-term (2 years) longitudinal analyses consisted of 1,243 monozygotic (MZ) twins and 1,751 dizygotic (DZ) twins, who participated in 1993 and 1995. For the long-term (7 years) longitudinal analyses the sample consisted of $839 \mathrm{MZ}$ twins and $957 \mathrm{DZ}$ twins, who participated in 1993 and 2000.

\section{Measures}

According to Van Dijck and Knibbe [33] people are problem drinkers if they drink above a certain threshold and if they experience problems related to their alcohol use. We assessed drinking problems in the twins in year 2 and 7 using the CAGE questionnaire, a widely used screening instrument for problem drinking $[4,30]$. The CAGE questionnaire derives its name from the acronym of four questions: "Have you ever felt you ought to cut down on your drinking?", "Have people annoyed you by criticizing your drinking?", "Have you ever felt bad or guilty about your drinking?", and "Have you ever had a drink first thing in the morning to steady your nerves or get rid of a hangover?" (eye opener). The questions were dichotomous: (1) "no" and (2) "yes". The score on the CAGE scale was established by summing the answers of the four questions [11]. Participants were also asked to report their quantity of drinking with the question: "how many drinks do you drink on average per week (including the weekend)?" This question had seven response categories (1) "less than 1 drink a week", (2) "1-2 drinks a week", (3) "3-5 drinks a week", (4) "6-10 drinks a week", (5) "11-20 drinks a week", (6) "21-40 drinks a week", and (7) "over 40 drinks a week" [25].

We defined problem drinking as at least one reported problem on the CAGE scale in combination with an alcohol consumption of at least 11 drinks a week. This resulted in a dichotomous variable: (1) "no problem drinker" and (2) "problem drinker". A cutoff point of one or more positive answers on the CAGE was shown to be the most valid cut-off point in adolescents [8]. Problem drinking of the adolescents and young adults was assessed in year 2 and 7 .

Frequency of drinking in twins was assessed at baseline with the question: "how often do you drink alcohol?" This question had eight response categories: (1) "I do not drink alcohol", (2) "once a year or less", (3) "a few times a year", (4) "about once a month", (5) "a few times a month", (6) "once a week", (7) "a few times a week", and (8) "daily". This item was recoded into: (1) "never/seldom", (2) "less than 12 times a year", (3) "a few times a month". We combined this measure with three zygosity categories: MZ, same sex $\mathrm{DZ}$ and dizygotic opposite sex (DOS) twins, resulting in a measure with nine categories. Missing data on frequency of drinking of co-twins could be completed by twins' reports on their co-twins' drinking, as these reports were highly correlated $(r=0.84, P<0.001)$.

Drinking of parents, siblings and friends was assessed at baseline to predict problem drinking of adolescents and young adults respectively 2 and 7 years later. Frequency of drinking for fathers and mothers was based on self-reports and was categorized as: (1) "never/seldom", (2) "a few times a week", and (3) "daily". In case data on alcohol use of father or mother were missing, data on alcohol use of year 2 were used ( $n=76$ for fathers and $n=59$ for mothers), because these were highly stable over time (for fathers $r=0.75, P<0.001$ and for mothers $r=0.78$, $P<0.001$ ). If these data were also not available, we used twin reports on their parents' alcohol use ( $n=219$ for fathers and $n=67$ for mothers). Correlation analyses showed a sufficient resemblance between twin reports and parents reports of parental frequency of drinking $(r=0.71, P<0.001$ for fathers' drinking, and $r=0.77, \quad P<0.001$ for mothers' drinking). In our sample 117 twins were from single parent (only mother) families, these families were excluded from further analyses as data on father's drinking was lacking.

At baseline, twins were asked about frequency of drinking of their brother(s) and sister(s) other than their co-twins. Based on these answers, drinking of non-twin siblings was categorized as: (1) "one or more brother(s) or sister(s) who seldom drink alcohol", (2) "one or more brother(s) or sister(s) who drink a few times a month alcohol", (3) "one or more brother(s) or sister(s) who drink a few times a week alcohol" and (4) "no additional brother(s) or sister(s)". There were 1,501 participants with at least one brother and 1,391 participants with at least one sister. When participants had more than one additional brother or sister, alcohol use of the most frequently 
drinking additional sibling was used to categorize the participants. At baseline, twins were also asked how many of their friends drank alcohol. Drinking of friends was categorized as: (1) "no drinking friend", (2) "a few friends drink", and (3) "more than half of the friends drink".

\section{Data analyses}

To determine whether drinking of family members and friends predicted problem drinking in adolescents and young adult twins we conducted multinomial logistic regression analyses for the short-term (1993-1995) and for the long-term (1993-2000) longitudinal data. In both analyses all predictor variables, including frequency of drinking of both twins, were assessed in 1993 while problem drinking of twins was assessed in 1995 and 2000. We used logistic regression analyses; age, sex, and respondents' own frequency of drinking in 1993 were entered in the model at the first analysis, thus in our analyses we controlled for these variables. Drinking of parents, co-twins, additional non-twin siblings and friends were entered in the model at the second analysis. Interaction terms between drinking of parents, co-twins, additional nontwin siblings and friends, and age and sex were entered in the model at the third and fourth analysis, respectively. These interaction terms were used to test whether the relations between family and friends' drinking and twins' alcohol use were different for 12 to 15,16 to 20 , for 21 to 25 -year olds, and also for males and females. In multinomial logistic regression the reference category obtains an odds ratio (OR) of 1 , the other categories (all at once) are contrasted against this reference category.

\section{Results}

\section{Prevalence rates of problem drinking}

Table 1 shows the prevalence rates of problem drinking for males and females in each age group. As can be seen in Table 1, males were more often problem drinkers than females. In 1995, among the 16 to 20 -year olds, $16 \%$ of the males as opposed to $5 \%$ of the females were problem drinkers. Among the 21 to 25 -year olds, these figures were 19 versus $7 \%$ for males and females, respectively. In the 2000 data, a similar pattern emerged. In each age group, about $30 \%$ of the males were problem drinkers, while these percentages were between 7 and $10 \%$ for females.

Results also showed that in 1995 age differences existed for males and females but that age differences were not significant in 2000. These differences in 1995
Table 1 The number $(n)$ and percentage of participants reporting problem drinking by age and sex (1995 $n=2,994 ; 2000 n=1,796)$

$\begin{array}{lllllllll}\text { Male } & & & \text { Female } \\ 12-15 & 16-20 & 21-25 & 26-30 & & 12-15 & 16-20 & 21-25 & 26-30\end{array}$

Problem drinking

$\begin{array}{lllllllll}1995(n) & 5 & 102 & 74 & 1 & 3 & 37 & 35 & 1\end{array}$

$\begin{array}{lllllllll}\% & 4.0 & 16.3 & 18.7 & 11.1 & 1.6 & 4.9 & 6.8 & 167\end{array}$

$\begin{array}{llllllll}2000(n)- & 32 & 111 & 52 & - & 17 & 59 & 25\end{array}$

$\begin{array}{lllllllll}\% & - & 33.3 & 31.3 & 28.6 & - & 9.9 & 10.3 & 6.7\end{array}$

Prevalence rates differed significantly between males and females (Chi-square tests $P<0.05$ ) except among 12 to 15 -year olds and 26 to 30 -year olds in 1995. Chi-square tests for sex differences ranged from $\chi^{2}(1, n=908)=29.98$, $P<0.001$ to $\chi^{2}(1, n=930)=64.84, P<0.001$

were caused by the prevalence in 12 to 15 and in 21 to 25 -year olds, as the difference in prevalence between 16 to 20 and 21 to 25 -year olds was not significant. Not surprisingly, only a very small percentage of the 12 to 15 -year olds were identified as problem drinkers. Because the 26 to 30 -year olds only contained a very small number of participants (nine males and six females), the figures concerning the percentage of problem drinkers in these groups should be interpreted with caution.

\section{Age and sex effects and drinking at baseline}

Tables 2 and 3 present the results of the multinomial logistic regression analyses in terms of OR and critical intervals (CI). Age of the participants in 1993 was not predictive of problem drinking over a 2-year period (1993-1995) but did predict problem drinking over the 7-year period (1993-2000). The results indicated that the youngest participants in 1993 were two to five times more likely to be problem drinkers in 2000 than were the 16 to 20 and 21 to 25 -year olds, respectively, because for the 16-20 old in 1993 an OR $=0.44$ (reciprocal OR $=2.27$ ) revealed in 2000 , and for the 21 to 25-year old in 1993 an OR $=0.18$ (reciprocal $\mathrm{OR}=5.56)$ in 2000. Both on the short-term and longterm, males were three to four times more at risk for problem drinking than were females: OR $=0.37$ (reciprocal $\mathrm{OR}=2.70$ ) in 1995 , and $\mathrm{OR}=0.25$ (reciprocal OR $=4.00$ ) in 2000. Moreover, participants who drank at least a few times a month in 1993 were of higher risk for problem drinking in 1995 and 2000 than those who never or seldom drank.

\section{Drinking of fathers, mothers, siblings and friends}

Paternal drinking was predictive for adolescent and young adult problem drinking, both over the 2- and 7 -year period. Adolescents and young adults whose 
Table 2 Short-term longitudinal associations between alcohol consumption of parents, siblings, and friends and problem drinking of adolescents and young adults $(1993-1995 n=2,994)$

\begin{tabular}{|c|c|c|}
\hline \multirow[t]{2}{*}{ Variable } & \multicolumn{2}{|c|}{ 1993-1995 } \\
\hline & OR & $95 \% \mathrm{Cl}$ \\
\hline \multicolumn{3}{|l|}{ Analysis 1} \\
\hline \multicolumn{3}{|l|}{ Age 1993 (year) } \\
\hline $12-15$ & 1 & \\
\hline $16-20$ & 1.24 & $0.71-2.15$ \\
\hline $21-25$ & 0.75 & $0.40-1.42$ \\
\hline \multicolumn{3}{|l|}{ Sex } \\
\hline Males & 1 & \\
\hline Females & $0.37^{* * *}$ & $0.27-0.50$ \\
\hline \multicolumn{3}{|l|}{ Alcohol use 1993} \\
\hline Never/seldom & 1 & \\
\hline A few times a year & 0.58 & $0.23-1.47$ \\
\hline A few times a month & $2.49^{*}$ & $1.10-5.64$ \\
\hline \multicolumn{3}{|l|}{ Analysis 2} \\
\hline \multicolumn{3}{|l|}{ Alcohol use father } \\
\hline Never/seldom & 1 & \\
\hline Few times a week & $2.24^{* *}$ & $1.37-3.65$ \\
\hline Daily & $1.95^{*}$ & $1.16-3.26$ \\
\hline \multicolumn{3}{|l|}{ Alcohol use mother } \\
\hline Never/seldom & 1 & \\
\hline Few times a week & $0.67^{*}$ & $0.47-0.94$ \\
\hline Daily & 0.81 & $0.52-1.24$ \\
\hline \multicolumn{3}{|l|}{ Alcohol use co-twin } \\
\hline MZ never/seldom & 1 & \\
\hline MZ a few times a year & 0.74 & $0.20-2.71$ \\
\hline $\mathrm{MZ}$ a few times a month & 1.47 & $0.46-4.68$ \\
\hline DZ never/seldom & 0.55 & $0.12-2.67$ \\
\hline DZ a few times a year & 1.33 & $0.38-4.69$ \\
\hline DZ a few times a month & 1.48 & $0.46-4.77$ \\
\hline DOS never/seldom & 1.19 & $0.30-4.68$ \\
\hline DOS a few times a year & 0.90 & $0.25-3.21$ \\
\hline DOS a few times a month & 1.48 & $0.46-4.75$ \\
\hline \multicolumn{3}{|l|}{ Alcohol use brother(s) } \\
\hline Seldom & 1 & \\
\hline Few times a month & 1.61 & $0.81-3.20$ \\
\hline Few times a week & 1.78 & $0.98-3.22$ \\
\hline No additional brother(s) & 1.50 & $0.87-2.58$ \\
\hline \multicolumn{3}{|l|}{ Alcohol use sister(s) } \\
\hline Seldom & 1 & \\
\hline Few times a month & $1.76^{*}$ & $1.03-3.02$ \\
\hline Few times a week & 1.44 & $0.79-2.62$ \\
\hline No additional sister (s) & 1.09 & $0.70-1.72$ \\
\hline \multicolumn{3}{|l|}{ Alcohol use friends } \\
\hline No one drinks & 1 & \\
\hline A few drink & 2.32 & $0.85-6.36$ \\
\hline More than half drink & $6.03^{* * *}$ & $2.24-16.23$ \\
\hline
\end{tabular}

MZ monozygotic, DZ dizygotic same sex, DOS dizygotic opposite sex ${ }^{*} P<0.05,{ }^{* * P}<0.01,{ }^{* * *} P<0.001$

Nagelkerke $R^{2}=0.25$ for the short-term longitudinal model with age, sex and alcohol use 1993

$\Delta$ Nagelkerke $R^{2}=0.05$ additionally for the short-term longitudinal model with age, sex, alcohol use 1993 and drinking behavior of family members and friends

fathers drank a few times a week in 1993 were about two times more likely to be a problem drinker in 1995 and 2000. Even more, when their fathers drank daily in 1993, they were also two times more likely to be problem drinker, but only over the 2-year period.
Table 3 Long-term longitudinal associations between alcohol consumption of parents, siblings, and friends and problem drinking of adolescents and young adults $(1993-2000 n=1,796)$

\begin{tabular}{|c|c|c|}
\hline \multirow[t]{2}{*}{ Variable } & \multicolumn{2}{|c|}{$1993-2000$} \\
\hline & $\mathrm{OR}$ & $95 \% \mathrm{Cl}$ \\
\hline \multicolumn{3}{|l|}{ Analysis 1} \\
\hline \multicolumn{3}{|l|}{ Age 1993 (years) } \\
\hline $12-15$ & 1 & \\
\hline $16-20$ & $0.44^{* * *}$ & $0.28-0.67$ \\
\hline $21-25$ & $0.18^{* * *}$ & $0.10-0.34$ \\
\hline \multicolumn{3}{|l|}{ Sex } \\
\hline Males & 1 & \\
\hline Females & $0.25^{* * *}$ & $0.18-0.33$ \\
\hline \multicolumn{3}{|l|}{ Alcohol use 1993} \\
\hline Never/seldom & 1 & \\
\hline A few times a year & 1.01 & $0.60-1.71$ \\
\hline A few times a month & $2.58^{* *}$ & $1.47-4.52$ \\
\hline \multicolumn{3}{|l|}{ Analysis 2} \\
\hline \multicolumn{3}{|l|}{ Alcohol use father } \\
\hline Never/seldom & 1 & \\
\hline Few times a week & $1.78^{*}$ & $1.13-2.81$ \\
\hline Daily & 1.46 & $0.90-2.36$ \\
\hline \multicolumn{3}{|l|}{ Alcohol use mother } \\
\hline Never/seldom & 1 & \\
\hline Few times a week & 0.89 & $0.64-1.25$ \\
\hline Daily & 0.98 & $0.65-1.49$ \\
\hline \multicolumn{3}{|l|}{ Alcohol use co-twin } \\
\hline MZ never/seldom & 1 & \\
\hline MZ a few times a year & 0.83 & $0.41-1.69$ \\
\hline MZ a few times a month & 1.32 & $0.68-2.57$ \\
\hline DZ never/seldom & 0.86 & $0.42-1.77$ \\
\hline DZ a few times a year & 1.25 & $0.58-2.70$ \\
\hline DZ a few times a month & 0.90 & $0.44-1.84$ \\
\hline DOS never/seldom & $2.18^{*}$ & $1.14-4.15$ \\
\hline DOS a few times a year & 0.86 & $0.38-1.95$ \\
\hline DOS a few times a month & 1.15 & $0.56-2.36$ \\
\hline \multicolumn{3}{|l|}{ Alcohol use brother(s) } \\
\hline Seldom & 1 & \\
\hline Few times a month & 0.77 & $0.43-1.40$ \\
\hline Few times a week & 0.87 & $0.52-1.46$ \\
\hline No additional brother(s) & 0.98 & $0.65-1.47$ \\
\hline \multicolumn{3}{|l|}{ Alcohol use sister(s) } \\
\hline Seldom & 1 & \\
\hline Few times a month & 1.44 & $0.84-2.45$ \\
\hline Few times a week & 1.74 & $0.93-3.24$ \\
\hline No additional sister (s) & 0.91 & $0.62-1.33$ \\
\hline \multicolumn{3}{|l|}{ Alcohol use friends } \\
\hline No one drinks & 1 & \\
\hline A few drink & 0.74 & $0.46-1.18$ \\
\hline More than half drink & 1.26 & $0.75-2.10$ \\
\hline
\end{tabular}

MZ monozygotic, DZ dizygotic same sex, DOS dizygotic opposite sex ${ }^{*} P<0.05$, ${ }^{* *} P<0.01$, ${ }^{* * *} P<0.001$

Nagelkerke $R^{2}=0.21$ for the long-term longitudinal model with age, sex and alcohol use 1993

$\Delta$ Nagelkerke $R^{2}=0.03$ additionally for the long- term longitudinal model with age, sex, alcohol use 1993 and drinking behavior of family members and friends

The predictive value of maternal drinking turned out to be lower than that of fathers. The only significant association was found for drinking a few times a week in relation to problem drinking in 1995: when mothers drank a few times a week in 1993, the adolescents and young adults were less at risk for prob- 
lem drinking than adolescents and young adults whose mothers never or seldom drank in 1993.

In general, alcohol use of the co-twin in 1993 was neither predictive of problem drinking in 1995 nor in 2000. The only exception was for adolescents and young adults whose DOS co-twin never or seldom drank in 1993: they had a higher risk for problem drinking in 2000 compared to twins who had a MZ cotwin who never or seldom drank in 1993. The alcohol use of additional brothers or sisters also turned out to have a low predictive value in general. Only adolescents who had a sister who drank a few times a month in 1993 were more likely to be a problem drinker in 1995, compared to participants who had a sister who never or seldom drank in 1993.

With regard to alcohol use of friends, our results showed that having a large number of drinking friends in 1993 was related to a substantial higher risk for problem drinking in 1995 compared to having no drinking friends in 1993. Having a few drinking friends in 1993 was not related to problem drinking.

Interactions between drinking of family members and friends, and age and sex were not significant. Thus the relation between family and friends' drinking and twins' alcohol use was not different for 12 to 15,16 to 20 and 21 to 25 -year olds, nor for males and females.

In addition, our analyses showed that the shortterm longitudinal model explained $30 \%$ of the variance in problem drinking, of which $25 \%$ was explained by age, sex and adolescents' and young adults' own alcohol use in 1993. The long-term longitudinal model with age, sex and own alcohol use in 1993 explained $21 \%$ of the variance in problem drinking. Adding family members' and friends' drinking to the model resulted in an additional 3\% of the explained variance.

\section{Discussion}

The main question we addressed in this study was to what extent adolescent and young adult problem drinking was predicted by drinking of family members (fathers, mothers, and siblings) and friends, over a period of 2 or 7 years, while accounting for the effect of age, sex, and own alcohol use.

Age, sex and own alcohol use were important predictors of problem drinking, but age and sex did not moderate the effects of family members and friends. With regard to age differences our study showed, in line with Silberg et al. [29], that people who were between 16 and 25 years of age in 1993 were at lower risk to be a problem drinker in 2000, when they were between 23 and 32, compared to participants who were 12-15 years old in 1993 and who were
19-22 in 2000. This finding is also in line with the finding by Van Dijck and Knibbe [33] who reported that among 25 to 34-year olds problem drinking was less prevalent than among 16 to 24 -year olds. This age effect might be explained by the fact that older adolescents and young adults were more likely to have finished their educational track and started working in 2000. Changes in social roles, such as the acquisition of a career, a spouse role and a parental role are to a large extent accountable for a drop in heavy and problem drinking [16]. This explanation is in line with a review study showing that risk factors for harmful alcohol use vary across different age groups [18]. Moreover as seen in other studies [13, 15, 33, 35], our results showed that males were at higher risk for problem drinking than females.

An important conclusion of our study is that adolescents and young adults with relatively high levels of alcohol use are of higher risk for problem drinking after 2 and even 7 years compared to adolescents and young adults with lower levels of alcohol use at baseline. This corroborates earlier studies showing that previous use is a strong predictor of current heavy and problematic drinking $[9,10,13$, 37]. Apparently, young people who drink at higher levels continue and accelerate their alcohol intake during adolescence and young adulthood resulting in subsequent problem drinking.

With regard to the impact of drinking of family members and friends, our findings indicated that adolescents and young adults who had fathers who frequently drank (i.e., a few times a week or daily) were twice as likely to be a problem drinking 2 or even 7 years later. This is in line with Ellickson et al. [10] who found an effect of fathers' drinking over a five year interval. The association between father's drinking and problem drinking could be interpreted as a modeling effect of children of their father's behavior. But it may also be, as indicated by McGue et al. [20], that genetic factors are involved in the relationship between father's alcohol use and problem drinking in their offspring. McGue et al. [20] arrived at this conclusion because they only found an association between drinking of biologically related parents and their offspring and not between parents and their adoptive offspring.

In contrast to paternal drinking, drinking of mothers, co-twins or other siblings was not substantially related to adolescents' future problem drinking. We expected to find significant associations between twins' drinking, because twins are generally more alike than singletons and we previously found a significant association between co-twin's drinking and regular alcohol use (in particular over a 2-year period) [26]. However, as twins are likely to be similar in their alcohol use, the effect of the co-twins could have 
been captured in participants' own alcohol use, and there was little variance left to be explained by drinking of the co-twin. To test this possibility, we examined whether the association between co-twin's drinking and adolescent and young adult drinking was stronger if we did not control for participants' alcohol use at baseline. These analyses did not result in higher predictive values for co-twins' drinking. Still, the fact that other family members were included may cloud this issue, as the association between cotwin's drinking and adolescent and young adult drinking more prominent if drinking of other family members and friends were not included in the analyses and of we did not control for age, sex and participants' alcohol use at baseline.

Comparison of associations of alcohol use within MZ co-twins with associations of alcohol use within DZ co-twins could be used to disentangle genetic and environmental effects on behavior. The comparison in this study did not reveal a consistent pattern of associations within $\mathrm{MZ}$ and $\mathrm{DZ}$ twin pairs. This might be explained by the fact that we assessed associations between one twin's frequency of use in 1993 with the other twin's problem drinking in 1995 and 2000, while in classical twin studies drinking of twins is assessed with identical measures at the same point in time. The relative importance of genetic and environmental effects on problem drinking in young people has been rarely studied, only Young et al. [40] showed that the variance in problem drinking in adolescents was for $53 \%$ explained by genetics and for $46 \%$ by environmental factors. All of these findings suggest that genes might play a role in problem drinking.

In line with studies on adolescent heavy alcohol use $[13,15,27,31]$ and problem drinking [10, 23, 37] our study showed that drinking of friends can be considered to have a strong influence on problem drinking in adolescents and young adults over a short period of time, in our study 2 years. However, over a longer time period (i.e. 7 years) drinking of friends did not add to the prediction of problem drinking. Possibly drinking of friends is not related to problem drinking later in life, but it is more likely that friendships changed during the assessment periods and that the adolescents and young adults made new friends with other drinking habits which outweighed the more distal effects of the former friends.

This study had a number of strengths, including a large sample, longitudinal data, and simultaneous examination of the impact of parents', siblings' and friends' drinking on adolescent and young adult problem drinking. However, while interpreting our results it should be noted that we used self-reports of parents and twins to assess their alcohol use, but that alcohol use of friends and additional siblings was reported by twins. This might have caused an overestimation of the effects of alcohol use of friends, since people tend to project their behavior to that of their friends, and perceived reports on drinking may therefore correlate more than actual reports [3]. In 1995 examination of self-reports of additional siblings as well as twin-reports over their siblings showed that these reports highly correlated (correlations around $0.74, P<0.001)$. This indicates that twins were very well capable of reporting on their siblings' alcohol use. We think that this also applies for twin reports on friends' drinking, thus our results are probably unbiased by overestimation of the effects of alcohol use of friends.

In conclusion, our study indicates that age, sex and own alcohol use explained a substantial part of the variance in adolescent and young adult problem drinking. Moreover, adolescents and young adults who had frequently drinking fathers and a large number of drinking friends, were at the highest risk for problem drinking 2 years later. Over a period of 7 years frequent alcohol use of fathers remained a risk factor for later problem drinking but the number of drinking friends was no longer a predictor of problem drinking. However, these effects explained only a small part of the variance in problem drinking compared to age, sex and own alcohol use. Drinking of other family members did not add much to the prediction of problem drinking. Our findings did not show sex and age differences in effects of family and friends' drinking.

\section{References}

1. Andrews JA, Tildesley E, Hops H, Li F (2002) The influence of peers on young adult substance use. Health Psychol 21:349-357

2. Ary DV, Tildesley E, Hops H, Andrews J (1993) The influence of parent, sibling, and peer modeling and attitudes on adolescent use of alcohol. Int J Addictions 28:853-880
3. Bauman KE, Ennett ST (1996) On the importance of peer influence for adolescent drug use: commonly neglected considerations. Addiction 91:185-198

4. Bisson J, Nadeau L, Demers A (1999) The validity of the CAGE scale to screen for heavy drinking and drinking problems in a general population survey. Addiction 94:715-722
5. Boomsma DI, Vink JM, Van Beijsterveldt TCEM, De Geus EJC, Beem AL, Mulder EJCM, Derks EM, Riese H, Willemsen G, Bartels M, Van den Berg M, Kupper NHM, Polderman TJC, Posthuma D, Rietveld MJH, Stubbe JH, Knol LI, Stroet T, Van Baal GCM (2002) Netherlands Twin Register: a focus on longitudinal research. Twin Res 5:401-406 
6. Boomsma DI, De Geus EJC, Vink JM, Stubbe JH, Distel MA, Hottenga JJ, Posthuma D, Van Beijsterveldt TCEM, Hudziak JJ, Bartels M, Willemsen G (2006) Netherlands Twin Register: from twins to twin families. Twin Res Hum Genet 9:849-857

7. Bot SM, Engels RCME, Knibbe RA, Meeus WHJ (2005) Friend's drinking behaviour and adolescent alcohol consumption: the moderating role of friendship characteristics. Addict Behav 30:929-947

8. Chung T, Colby SM, Barnett NP, Rohsenow DJ, Spirito A, Monti PM (2000) Screening adolescents for problem drinking: performance of brief screens against DSM-IV alcohol diagnoses. J Stud Alcohol 61:579-587

9. Duncan SC, Alpert A, Duncan TE, Hops H (1997) Adolescent alcohol use development and young adult outcomes. Drug Alcohol Depend 49:39-48

10. Ellickson PL, Tucker JS, Klein DJ, McGuigan KA (2001) Prospective risk factors for alcohol misuse in late adolescence. J Stud Alcohol 62:773-782

11. Ewing JA (1984) Detecting alcoholism. The CAGE questionnaire. J Am Med Assoc 252:1905-1907

12. Graham JW, Marks G, Hansen WB (1991) Social influence processes affecting adolescent substance use. J Appl Psychol 76:291-298

13. Griffin KW, Botvin GJ, Epstein JA, Doyle MM, Diaz T (2000) Psychosocial and behavioral factors in early adolescence as predictors of heavy drinking among high school seniors. J Stud Alcohol 61:603-606

14. Gruber E, DiClemente RJ, Anderson MM, Lodico M (1996) Early drinking onset and its association with alcohol use and problem behavior in late adolescence. Prev Med 25:293-300

15. Guilamo-Ramos V, Turrisi R, Jaccard J, Wood E, Gonzalez B (2004) Progressing from light experimentation to heavy episodic drinking in early and middle adolescence. J Stud Alcohol 65:494-500

16. Hajema KJ, Knibbe RA (1998) Changes in social roles as predictors of changes in drinking behaviour. Addiction 93:1717-1727

17. Hingson R, Heeren T, Zakocs R, Winter M, Wechsler H (2003) Age of first intoxication, heavy drinking, driving after drinking and risk of unintentional injury among U.S. college students. J Stud Alcohol 64:23-31
18. Loxley W, Toumbourou JW, Stockwell T, Haines B, Scott K, Godfrey C, Waters E, Patton G, Fordham R, Gray D, Marshall J, Ryder D, Saggers S, Sanci L, Williams J (2004) The prevention of substance use, risk and harm in Australia: a review of the evidence. The National Drug Research Centre and the Centre for Adolescent Health, Canberra

19. McCarty CA, Ebel BE, Garrison MM, DiGiuseppe DL, Christakis DA, Rivara FP (2004) Continuity of binge and harmful drinking from late adolescence to early adulthood. Pediatrics 114:714719

20. McGue M, Sharma A, Benson P (1996) Parent and sibling influences on adolescent alcohol use and misuse: Evidence from a U.S. adoption cohort. J Stud Alcohol 57:8-18

21. Statistics Netherlands (2004) http://www.cbs.nl/nl/cijfers/statline

22. O'Neill SE, Parra GR, Sher KJ (2001) Clinical relevance of heavy drinking during the college years: cross-sectional and prospective perspectives. Psychol Addict Behav 15:350-359

23. Ouellette JA, Gerrard M, Gibbons FX, Reis-Bergan M (1999) Parents, peers, and prototypes: antecedents of adolescent alcohol expectancies, alcohol consumption, and alcohol-related life problems in rural youth. Psychol Addict Behav 13:183-197

24. Petraitis J, Flay BR, Miller TQ (1995) Reviewing theories of adolescent substance use: organizing pieces in the puzzle. Psychol Bull 117:67-86

25. Poelen EAP, Scholte RHJ, Engels RCME, Boomsma DI, Willemsen G (2005) Prevalence and trends of alcohol use and misuse among adolescents and young adults in the Netherlands from 1993 to 2000. Drug Alcohol Depend 79:413-421

26. Poelen EAP, Scholte RHJ, Willemsen G, Boomsma DI, Engels RCME (2007) Drinking of parents, siblings, and friends as predictors of regular alcohol use in adolescents and young adults: a longitudinal twin-family study. Alcohol Alcohol 42:362-369

27. Reifman A, Barnes GM, Dintcheff BA, Farrell MP, Uhteg L (1998) Parental and peer influences on the onset of heavier drinking among adolescents. J Stud Alcohol 59:311-317

28. Schulenberg JE, Maggs JL (2002) A developmental perspective on alcohol use and heavy drinking during adolescence and the transition to young adulthood. J Stud Alcohol Suppl 14:54-70

29. Silberg J, Rutter M, D’Onofrio B, Eaces L (2003) Genetic and environmental risk factors in adolescent substance use. J Child Psychol Psychiatry 44:664-676
30. Smart RG, Adlaf EM, Knoke D (1991) Use of the CAGE scale in a population survey of drinking. J Stud Alcohol 52:593-596

31. Tucker JS, Orlando M, Ellickson PL (2003) Patterns and correlates of binge drinking trajectories from early adolescence to young adulthood. Health Psychol 22:79-87

32. Urberg KA, Değirmencioğlu SM, Pilgrim C (1997) Close friend and group influence on adolescent cigarette smoking and alcohol use. Dev Psychol 33:834-844

33. Van Dijck D, Knibbe RA (2005) De prevalentie van probleemdrinken in Nederland: Een algemeen bevolkingsonderzoek [The prevalence of problem drinking in the Netherlands: a general population study]. Universiteit Maastricht, Maastricht

34. Vink JM, Willemsen G, Stubbe JH, Middeldorp CM, Ligthart RSL, Baas K, Dirkzwager H, De Geus E, Boomsma DI (2004) Estimating non-response bias in family studies: application to mental health and lifestyle. J Epidemiol 19:623-630

35. Walden B, Iacono WG, McGue M (2007) Trajectories of change in adolescent substance use and symptomatology: Impact of paternal and maternal substance use disorders. Psychol Addict Behav 21:35-43

36. Wechsler H, Davenport A, Dowdall G, Moeykens B, Castillo S (1994) Health and behavioral consequences of binge drinking in college: a national survey of students at 140 campuses. J Am Med Assoc 272:1672-1677

37. Windle M (2000) Parental, sibling, and peer influences on adolescent substance use and alcohol problems. Appl Dev Sci 4:98-110

38. Wood MD, Read JP, Palfai TP, Stevenson JF (2001) Social influence processes and college student drinking: the mediational role of alcohol outcome expectancies. J Stud Alcohol 62:32-43

39. Wood MD, Read JP, Mitchell RE, Brand NH (2004) Do parents still matter? Parent and peer influences on alcohol involvement among recent high school graduates. Psychol Addict Behav 18:1930

40. Young SE, Rhee SH, Stallings MC, Corley RP, Hewitt JK (2006) Genetic and environmental vulnerabilities underlying adolescent substance use and problem use: general or specific? Behav Genet 36:603-615 